\title{
El matrimonio de Felipe V y la alianza borbónico-saboyana de 1701*
}

\author{
José Antonio López Anguita ${ }^{1}$ \\ UCM Universidad de Mayores del Ilustre Colegio Oficial de Doctores y \\ Licenciados en Filosofía y Letras y Ciencias (Madrid) \\ joalopez@ghis.ucm.es
}

RESUMEN: Tras la entronización de Felipe V como rey de España, y ante el inminente estallido de un conflicto por la sucesión de Carlos II, Francia y la Monarquía Hispánica dieron inicio a una intensa política de alianzas destinada a neutralizar las pretensiones de la rama vienesa de la Casa de Austria sobre la corona española. La península itálica, donde los Borbones contarían con la adhesión de los ducados de Mantua y Saboya, fue un escenario prioritario en el desarrollo de tal política. Este artículo pretende analizar el papel que jugaron las nupcias de Felipe Vy María Luisa de Saboya en la formalización del tratado borbónico-saboyano de abril de 1701. Basándonos en la documentación de carácter diplomático ubicada en los archivos franceses, españoles e italianos, insistiremos no sólo en las características del acuerdo firmado entre ambas dinastías, sino también en cómo la negociación del matrimonio regio se vio influida por la fragilidad de una alianza políticamente asimétrica que terminaría rompiéndose apenas dos años después de su establecimiento.

\section{Palabras Clave: Francia; Monarquía Hispánica; Saboya; diploma- cia; alianza; Luis XIV; Felipe V; Víctor Amadeo II.}

* Esta investigación se inserta en el proyecto MINECO «Élites financieras y burocráticas de la Monarquía Hispánica: redes de solidaridad nobiliaria, patronazgo y estrategias de familia (1621-1725)», HAR2015-69143-P.

Abreviaturas utilizadas: Archivo General de Simancas (AGS); Archivo Histórico Nacional (AHN); Archive du Ministère des Affaires Étrangères, París (AMAEP); Archivio di Stato di Torino (AST); Biblioteca Nacional de España (BNE); Correspondance politique Espagne (CPE); Correspondance Politique Sardaigne-Savoie (CPS); Estado (E); Lettere Ministri Spagna (LMS); Lettere Ministri Francia (LMF).

1 ORCID iD: http://orcid.org/0000-0002-8030-2011. 


\section{The marriage of Philip V and the Bourbon-Savoyard Alliance of 1701}

ABSTRACT: After the coronation of Philip $V$ as King of Spain and the imminent outbreak of war caused by Charles II's succession, both the French and the Spanish Monarchy entered into different diplomatic alliances in order to neutralize claims from the Viennese branch of the House of Austria to the Spanish crown. The Italian Peninsula, where France and the Spanish Monarchy had the support of the duchies of Mantua and Savoy, was an important scenario for Bourbon diplomacy. This article aims to analyse the role played by the marriage of Philip V and Mary Louise of Savoy in the signing of the Bourbon-Savoyard Treaty, in April 1701. Based on diplomatic sources located in Spanish, French and Italian archives, this paper focuses not only on the characteristics of the agreement signed between the two dynasties, but also on how the negotiations for the King's marriage were influenced by the fragility of a politically asymmetric alliance which would break apart just two years after its formalization.

KEY WORDS: France; Spanish Monarchy; Savoy; Diplomacy; alliance; Louis XIV; Philip V; Victor Amadeus II.

CÓMO CITAR ESTE ARTICULO/CITATION: López Anguita, José Antonio, «El matrimonio de Felipe V y la alianza borbónico-saboyana de 1701», Hispania, 77/257 (Madrid, 2017): 735-762. doi: 103989/hispania.2017.020.

\section{El MATrimonio de Felipe V y la AlianZa Borbónico-SABoyana de 1701}

Las nupcias de Felipe V y María Luisa de Saboya suscitaron el rechazo de ciertos contemporáneos e historiadores posteriores (desde Saint-Hilaire a Michelet), que deploraron cómo Luis XIV, un «grand roi, trop fier de sa grandeur [...], de sa puissance», se había dejado manipular por los artificios de un soberano italiano menor, el duque de Saboya, arrastrando a Francia a une «guerre longue et périlleuse qui a ruiné le royaume et l'a mis à deux doigts de sa perte $\iota^{2}$. Semejante percepción, basada tanto en el fracaso de la posible unión entre el monarca español y una hija del emperador Leopoldo I como en la traición de Víctor Amadeo II a los Borbones (1703), resulta absolutamente errónea. De entrada, porque el matrimonio de Felipe $\mathrm{V}$ con una princesa saboyana no precipitó en ningún caso el estallido del conflicto sucesorio. Como es bien sabido, otros factores, entre ellos algunas de las iniciativas de Luis XIV a lo largo de 1701, resultaron más determinantes a este respecto. Pero también porque tales nupcias no influyeron en la posterior ruptura de la coalición borbónico-saboyana. Si esta fracasó en 1703 se debió al modo en que

2 LECESTRE, 1909, vol. III: 106-107. Las opiniones de Saint-Hilaire serían compartidas por su coetáneo, el caballero de Quincy, y recogidas y ampliadas un siglo y medio después por Jules Michelet. LECESTRE, 1898, vol. I: 152-153; 313. MICHELET, 2008, vol. XIV: 139-142. 
Versalles negoció una alianza «políticamente asimétrica» ${ }^{3}$, cierto, pero no por ello menos trascendente dada la coyuntura: mediante un autoritarismo incapaz de reconocer no sólo los potenciales intereses de la corte de Turín a corto y medio plazo, sino también la importancia geoestratégica del ducado para una Francia que debía proteger la Italia española ${ }^{4}$.

Este artículo pretende analizar el papel que jugaron las nupcias de Felipe $\mathrm{V}$ en el devenir de la alianza borbónico-saboyana de abril de 1701; un papel que en ningún caso debe ser desdeñado por cuanto influyó, en un principio y junto con otros factores, en la adhesión de Saboya a la Casa de Borbón. Basándonos en la documentación de naturaleza diplomática que albergan los archivos franceses, españoles e italianos incidiremos, en primer término, en la posición del ducado en las relaciones internacionales europeas en los últimos años del siglo XVII; en segundo lugar, abordaremos la gestación y características del acuerdo entre Saboya y las dos Coronas. Por último analizaremos el desarrollo de la negociación matrimonial en sí misma, insistiendo en cómo esta se vio influida por el devenir de la alianza en más de un sentido.

\section{SABOYA Y LA GEOPOLÍTICA DEL NORTE DE ITALIA}

Estado tapón enclavado entre los territorios bajo soberanía de Francia y la Monarquía Hispánica, el ducado de Saboya ${ }^{5}$ ocupaba una estratégica posición geográfica que favoreció su participación en la rivalidad francoespañola durante los siglos XVI y XVII. Pieza clave en la geopolítica del norte de Italia, pocos testimonios expresan de manera más explícita la importancia del ducado para ambas Coronas que una Consulta del Consejo de Estado fechada en 1697. En ella el gobierno español cifraba la «seguridad de los dominios de Italia» en la «amistad y buena correspondencia con la Casa de Savoia, cuio estado, por su poder y situación [...] era como la valanza que hacia donde se inclinase era el bien y la conveniencia» ${ }^{6}$.

Hasta la década de 1630 la corte de Turín se mantuvo relativamente bajo la órbita de la Monarquía Hispánica. No obstante, el establecimiento de guarni-

3 Según el término empleado por Spagnoletti para referirse a la política matrimonial de las dinastías italianas. SPAGNOLETTI, 2003.

4 A este respecto no deja de resultar llamativo que el autoritarismo con el que Luis XIV actuó ante Saboya no fuera tan evidente en las negociaciones que Versalles llevó a cabo con su otro gran aliado de 1701, el Portugal de Pedro II. MARTIN MARCOS, 2014: 146-151.

5 Conocido con el nombre genérico de ducado de Saboya, el estado saboyano comprendía diferentes territorios como el principado de Piamonte, el ducado de Aosta, el condado de Niza o el principado de Oneglia, entre otros, dotados de una entidad jurisdiccional específica y vinculados por el gobierno de un soberano común. SYMCOX, 1983a: 18-66; 2007: 49-86.

6 Consulta del Consejo de Estado, Madrid, 18 de marzo de 1697, AGS, E, leg. 3569. 
ciones francesas en las fortalezas de Pinerolo y Casale, en 1631 y 1681 respectivamente, hizo del ducado un satélite de Francia. Esta circunstancia, favorecida además por los sucesivos periodos de regencia encabezados por sendas duquesas de origen francés, condicionó las opciones del estado saboyano en política exterior y, más concretamente, en lo que se refería a sus relaciones con Madrid7. «La fuerza que hace acá el miedo de la Francia», en palabras del embajador español en Turín, duque de Giovenazzo, neutralizó cualquier posible acercamiento diplomático entre Saboya y la Monarquía Hispánica durante buena parte de la segunda mitad del siglo XVII ${ }^{8}$.

Sería en 1690, en el contexto de la Guerra de los Nueve Años, que enfrentó a Francia con Inglaterra, las Provincias Unidas, el Imperio y la Monarquía Hispánica, cuando el ducado pudo sustraerse de la tutela ejercida por Luis XIV sobre su política exterior. El conflicto, al que puso fin la Paz de Ryswick de 1697, manifestó la capacidad de Víctor Amadeo II para sacar partido de la coyuntura que dominaba las relaciones internacionales a la sazón. Ciertamente, una parte importante del estado saboyano fue devastada durante la guerra. Sin embargo, el duque suscribió importantes acuerdos diplomáticos con los aliados (que ofrecieron subsidios económicos y refuerzos militares a cambio de la participación de Saboya en el conflicto). Asimismo, una vez que la ayuda aliada se reveló insuficiente, Víctor Amadeo II negoció unilateralmente con Francia la paz de Turín (1696), que devolvió al ducado la posesión de Pinerolo, neutralizó Casale y estipuló el matrimonio de su primogénita, María Adelaida, con el nieto de Luis XIV y futuro heredero del trono francés, el duque de Borgoña9 .

Para Saboya, el balance de la Guerra de los Nueve Años fue paradójico en cierto modo. Por un lado el prestigio de la dinastía salió reforzado merced a una nueva unión con la Casa de Borbón ${ }^{10}$, al tiempo que el duque obtuvo de las principales cortes europeas (Londres, Madrid, Viena y Versalles) el reco-

7 Acerca de la posición del ducado de Saboya en las relaciones internacionales, BÉLY, 2002: 225-236. STORRS, 2007: 3-47. Sobre el periodo de «Regencias» véanse ROSSO, 2008: 367-392 y ORESKO, 2008: 393-434. Para una historia del ducado durante la época moderna, GALASSO, 1994.

8 Despachos del duque de Giovenazzo, Turín, 5 de enero de 1678, AGS, E, leg. 3652; la respuesta del Consejo de Estado a Giovenazzo, fechada en Madrid, 20 de enero de 1678, AGS, E, leg. 3669.

9 Sobre las negociaciones entre Saboya y los aliados, SYMCOX, 1983b:151-184. STORRS, 22/3 (Londres, 1992): 347-381; 2013: 134-135 y 199. Para la Paz de Turín y sus antecedentes, véanse HANDEN, 1976: 241-260. ROWLANDS, 115/462 (Oxford, 2000): 534569. Acerca de la actividad de la diplomacia saboyana en este periodo, MOSCATI, 1941. STORRS, 1999; 2000: 210-252.

10 La esposa de Víctor Amadeo II era una princesa francesa, Ana María de Orleáns, sobrina de Luis XIV y hermana de María Luisa de Orleáns, primera esposa de Carlos II. REINERI, 2006. 
nocimiento del trattamento reale ${ }^{11}$. Por otro lado, la Paz de Turín enrareció las relaciones de Saboya con sus anteriores aliados (principalmente con las potencias marítimas), lo que favoreció un cierto aislamiento diplomático que a corto plazo restó potencialidad a la política exterior del ducado tras la evacuación de Pinerolo por los franceses ${ }^{12}$.

Desde estas perspectivas no es extraño que en los últimos años del siglo XVII, dominados por el debate en torno a la herencia de Carlos II, Saboya debiera depender de Francia para participar, si bien de manera indirecta, en el problema sucesorio español ${ }^{13}$. Consciente de las ambiciones expansionistas del duque en Lombardía, Luis XIV aprovechó el contenido del último tratado de reparto de la Monarquía Hispánica, suscrito entre Francia y las potencias marítimas, para negociar con Víctor Amadeo II los preliminares de un acuerdo cuyos términos se decidieron a medios de octubre de 1700. En concreto, Luis XIV propuso al duque una permuta de territorios: el ducado de Saboya, el condado de Niza y el valle de la Barceloneta pasarían a Francia a cambio del Milanesado español, la principal ambición de Víctor Amadeo II, quien además conservaría el resto de sus estados patrimoniales ${ }^{14}$. En su biografía sobre el duque, Symcox duda de la honestidad de las intenciones de Luis XIV al negociar dicho acuerdo, cuyo verdadero objetivo habría sido el de neutralizar las posibles conversaciones del gobierno saboyano con Viena, otra de las partes implicadas en el problema sucesorio ${ }^{15}$.

El advenimiento de Felipe $\mathrm{V}$ al trono español eliminó la anterior rivalidad francoespañola en la corte de Turín. Francia y la Monarquía Hispánica presentaban ahora un frente común en las relaciones internacionales, según constataban las órdenes del soberano francés para que los diplomáticos españoles

11 El trattamento reale derivaba de las pretensiones ducales a la extinta corona de Chipre. Su reconocimiento implicaba no sólo la elevación del duque y sus sucesores a la dignidad de «Alteza Real», sino también la concesión a los diplomáticos saboyanos de los mismos honores que disfrutaban en las cortes europeas los representantes de la realeza de mayor rango y algunas repúblicas como Venecia. ORESKO, 1997: 272-350.

12 SYMCOX, 1983a: 117.

13 Sobre los Tratados de Reparto, BÉLY, 2013: 51-75. Una obra de carácter general sobre dichos acuerdos, con artículos específicos acerca de los intereses franceses, holandeses, británicos y saboyanos en la sucesión española, en RIBOT e IÑURRITEGUI, 2016. La significación del problema sucesorio español en el contexto de las relaciones internacionales europeas de finales del siglo XVII ha sido tratada en BÉRENGER, 2003: 75-91. MALETTKE, 2003: 93-100. RIBOT, 2016: 29-53. Una visión desde la diplomacia saboyana en RIVA, 2016: 199-213.

14 SYMCOX, 1983a: 137-138. STORRS, 2016: 217-245. Aunque el trabajo de Storrs se centra especialmente en las relaciones anglo-saboyanas durante el último cuarto del siglo XVII, en él se encuentran referencias a los intercambios territoriales planteados por Luis XIV entre 1699 y 1700 , véanse en especial las páginas 238-239.

15 SYMCOX, 1983a: 138. 
actuasen de concierto, y bajo las directrices, de sus homólogos franceses ${ }^{16}$. Esta circunstancia incrementó la importancia geoestratégica del estado saboyano para las dos Coronas, principalmente cuando la negativa de Leopoldo I a reconocer a Felipe V como rey de España hizo inevitable el futuro estallido de un conflicto por la sucesión de Carlos II.

Consciente de que en ese momento las ambiciones del emperador se centraban en la Italia española ${ }^{17}$, Luis XIV aspiró a formar una liga de príncipes italianos que, con el apoyo de Francia, pudiera oponerse a la invasión planeada por los ejércitos imperiales. Las negociaciones, emprendidas por el conde de Tessé y el cardenal d'Estrées, embajador francés en Roma, distaron de concluir exitosamente. Con la excepción del duque de Mantua, los gobernantes del norte de Italia (Módena, Parma, Toscana, Venecia y Génova) se decantaron por la neutralidad, defendida asimismo por el Papa, quien aspiraba alejar la guerra de tierras italianas ${ }^{18}$.

Pese al fracaso de los diplomáticos galos, la percepción de los resultados de la diplomacia borbónica en la península Itálica a finales de 1700 fue variable, en buena medida debido a la creencia en la superioridad de las armas francesas sobre las imperiales ${ }^{19}$. En cualquier caso, de lo que no cabía duda era de la trascendencia de Saboya para la estrategia militar francoespañola y,

16 BÉLY, 2007: 418.

17 A la sazón Leopoldo I no había logrado vencer la reticencia de Inglaterra y las Provincias Unidas a intervenir en un conflicto por la sucesión española, lo que llevó a Viena a concentrar sus esfuerzos en la península Itálica. La ratificación por el Parlamento de París de los derechos sucesorios de Felipe V a la corona de Francia, el reconocimiento de Jacobo III Estuardo como rey de Inglaterra y la entrada de tropas francesas en las fortalezas de la Barrera, llevaron a las potencias marítimas a abandonar su neutralidad y a aliarse con el Imperio en la conocida como Gran Alianza de la Haya (septiembre de 1701). THOMSON, 1968: 140-159. NORDMANN, 1976: 82-111. FREY, 1983: 56-57. BÉRENGER, 2004: 426; 2007: 73-84. KAMPMANN, 2016: 191-193. Sobre la gestación de esta nueva coalición europea contra la Casa de Borbón, ARROYO VOZMEDIANO, 2012: 228-236.

18 GRIMOARD, 1806, vol. I: 189. Sobre la política italiana de Luis XIV, MEUVRET, 46-47 (París, 1960): 84-102. BÉLY, 2007: 417-421. Para un análisis de los intereses políticos, diplomáticos y geoestratégicos de Francia en el norte de Italia entre 1635 y 1659, consúltese la obra de BLUM, 2014, en especial su primera parte. Acerca del papel de la Santa Sede en los inicios del conflicto sucesorio, MARTÍN MARCOS, 2011: 61-82. Una visión general de la situación de Italia durante la Guerra de Sucesión en MURGIA, 2009: 187-229.

19 Tal era la impresión del marqués de Castelldosrius, embajador español en Francia. Carta de Castelldosrius al duque de Paretti, embajador español en Viena, París, 23 de enero de 1701, AHN, E, leg. 1661. Asimismo, para el marqués la neutralidad de Venecia, otro de los puntos estratégicos en el conflicto, distaba de ser perjudicial para los intereses borbónicos, en tanto en cuanto permitía a los «imperiales franquearse el passo [a través de su territorio desde el Tirol] y a las dos Coronas [...] impedírselo [...]». Carta de Castelldosrius al Consejo de Estado, París, 26 de junio de 1701, AHN, E, leg. 1660. El conde de Tessé albergaba una opinión similar. GRIMOARD, 1806, vol. I: 189-190. 
por lo tanto, de la necesidad de impedir que el ducado siguiera el mismo camino que otras soberanías de la Italia septentrional.

\section{Saboya ANTE la Guerra de SuCEsión ESPañola: PRIMERAS CONVERSA- CIONES ENTRE VERSALLES, MADRID Y TURÍN}

El inminente estallido del conflicto sucesorio hizo de Saboya una pieza clave en el sistema de alianzas de la Casa de Borbón. La Guerra de los Nueve Años había constatado la potencialidad de la ubicación del ducado, base privilegiada desde la que poner en jaque tanto las defensas del Milanesado español como algunos puntos estratégicos del sureste francés: el Lyonnais, el Delfinado, el Franco Condado y la Provenza, donde se encontraba la importante base naval de Toulon ${ }^{20}$. A este hecho había que añadir que, en los primeros años de la Guerra de Sucesión, Francia no sólo debía velar por la seguridad de sus fronteras sino también por la integridad del ducado de Milán, objeto de las ambiciones imperiales, cuyas dificultades defensivas preocupaban a su entonces gobernador, el príncipe de Vaudemont ${ }^{21}$. En consecuencia, obtener el control de los pasos alpinos, que comunicaban el territorio francés con Saboya, y garantizar el libre tránsito de los ejércitos de las dos Coronas a través del estado saboyano, se convirtió en una prioridad para la diplomacia borbónica.

El problema en esos momentos radicaba en la dificultad de Versalles, Madrid y Turín para conciliar sus objetivos respecto a una posible alianza. Como no tardó en apreciar el conde de Vernon, embajador saboyano en Francia ${ }^{22}$, para Luis XIV era impensable suscribir cualquier acuerdo con Saboya sobre la base de los preliminares de octubre de 1700, que contemplaban un intercambio territorial que habría puesto el Milanesado en posesión de Víctor Amadeo II. Ceder en este punto, el principal atractivo que presentaba para el duque la firma de un tratado con los Borbones, no sólo habría supuesto una flagrante vulneración de la integridad territorial de la Monarquía Hispánica,

20 ROWLANDS, 115/462 (Oxford, 2000): 536. BEAUCAIRE, 1898: 248.

21 Parte de la correspondencia de Vaudemont con la Junta de Gobernación, que rigió los destinos de la Monarquía hasta la llegada a España de Felipe V, se encuentra en AHN, E, leg. 1976. Juan Carlos Bazán, enviado español en Turín hasta 1700, también aludió a la carencia de pertrechos y armamento de las principales plazas fuertes de Nápoles y Sicilia. Carta de Bazán al conde de Oropesa. Turín, 17 de abril de 1698, BNE, mss. 3527, fol. 102v. La evolución del Milanesado durante el conflicto sucesorio ha sido analizada por ÁLVAREZ-OSSORIO, 2004, vol. I: 775-842. Sobre la figura de Vaudemont, CREMONINI, 2007: 463-490.

22 Desde principios de noviembre de 1700 Vernon informó a Turín de sus sospechas respecto a las intenciones de Versalles en relación al Milanesado, que se vieron corroboradas tras una reunión que mantuvo con Torcy el día 11, poco después de hacerse pública la aceptación del testamento de Carlos II. Despachos del conde de Vernon, Fontainebleau, 7 y 11 de noviembre de 1700, AST, LMF, Mazzo 128. 
que Francia aspiraba a salvaguardar por el momento, sino que también habría concitado la oposición del gobierno español.

En este contexto, las nupcias de Felipe V con una princesa saboyana se convirtieron en una baza fundamental a través de la que garantizar la adhesión de Saboya a las dos Coronas. Ciertamente, el testamento de Carlos II estipulaba el enlace de su sucesor con una archiduquesa de Austria, posibilidad que contaba a su vez con cierto respaldo en la corte madrileña ${ }^{23}$. Sin embargo, no parece que Leopoldo I y Luis XIV, como tampoco el cardenal Portocarrero, figura destacada del gobierno español en los primeros tiempos del nuevo reinado, contemplaran seriamente tal eventualidad. Para el emperador, aceptar el matrimonio de una de sus hijas con Felipe V hubiera entrañado el reconocimiento del Borbón como rey de España, su renuncia a la herencia de Carlos II y el abandono de sus pretensiones iniciales sobre los territorios italianos de la Monarquía Hispánica ${ }^{24}$. En cuanto a Luis XIV y Portocarrero, durante algún tiempo el primero aparentó mostrarse favorable a tal unión, pero no llegó a realizar ninguna petición oficial a Viena. De hecho, conforme pasaron las semanas el monarca francés comenzó a valorar los inconvenientes de un enlace semejante. Tal y como escribió a su embajador en Madrid, convertir a una archiduquesa en esposa de su nieto no sólo pondría en riesgo la necesaria unión entre ambas ramas de la Casa de Borbón sino que también podría alentar la inestabilidad de la corte española, donde el emperador contaba aún con algunos partidarios ${ }^{25}$. Las razones por las que Portocarrero rechazaba la opción imperial eran de índole personal. Decidido partidario de la sucesión borbónica en los últimos meses de vida de Carlos II, el cardenal consideraba que una consorte Habsburgo se opondría, a instancias de Leopoldo I, a la continuidad de su influencia sobre la toma de decisiones en el gobierno español ${ }^{26}$. Finalmente, las posibilidades de que una archiduquesa acabara casada con Felipe V se vieron perjudicadas por la impopularidad en

$23 \mathrm{Al}$ menos eso es lo que se desprende de algunos testimonios contemporáneos, como el del diplomático Bernardo Bravo, quien escribió al barón de Prielmayer: «[...] Es cierto que esta nación más hubiera deseado una hija del Emperador como medio para la paz, a que se inclina, por temor de los peligros y gastos que trae consigo la guerra [...].» Carta de Bernardo Bravo a Prielmayer. Madrid, 19 de mayo de 1701, BAVIERA, GAMAZO, 2004, vol. II: 1415.

24 BÉRENGER, 2004: 426. KAMPMANN, 2016: 192.

25 Véase la correspondencia de Luis XIV con el duque de Harcourt. HIPPEAU, 1875, vol. II: 413-414. También los Despachos de Lorendan, enviado veneciano ante la corte imperial. Viena, 8 de enero de 1701, NICOLINI, 1937, vol. I: 293.

26 Ese fue el argumento con el que el embajador veneciano en Madrid, Mocénigo, justificó la oposición de Portocarrero al matrimonio de Felipe V con una archiduquesa. Despachos de Mocénigo. Madrid, 6 de enero de 1701, NICOLINI, 1937, vol. I: 282. En cualquier caso, para el mes de abril el cardenal defendía firmemente la opción matrimonial saboyana. Despachos de Operti. Madrid, 28 de abril de 1701, AST, LMS, Mazzo 48. 
Madrid de algunos sujetos de origen alemán vinculados al entorno de Mariana de Neoburgo: «están muy recientes las antipatías que despertaron las supuestas malas acciones de algunos alemanes [...]», concluyó el doctor Geelen, médico de la reina viuda ${ }^{27}$.

Frente a los problemas que representaba un matrimonio imperial, la de María Luisa de Saboya constituía una opción viable en un mercado matrimonial regio en el que no abundaban las princesas en edad casadera. Aunque aún no era núbil, lo que demoraba la perspectiva de una próxima sucesión, María Luisa contaba con un impecable capital dinástico ${ }^{28}$; había recibido una cuidada educación en un entorno francés, y profesaba la religión católica ${ }^{29}$. Además, factores diplomáticos y geopolíticos aparte, las nupcias de Felipe V y María Luisa de Saboya contribuirían a reforzar los vínculos entre ambas ramas de la Casa de Borbón, habida cuenta que la futura desposada era la hermana menor de la duquesa de Borgoña ${ }^{30}$.

Con estas consideraciones presentes, Versalles planteó el enlace del rey de España con la princesa María Luisa en diciembre de 1700. Las primeras iniciativas a este respecto, llevadas a cabo por el secretario de Estado de Asuntos Exteriores francés, marqués de Torcy, fueron acogidas con circunspección por el embajador saboyano en Francia, conde de Vernon. Carente de instruc-

27 Carta del Doctor Geelen al elector palatino. Madrid, 7 de septiembre de 1701, BAVIERA, GAMAZO, 2004, vol. II: 1419. La impopularidad de la opción imperial era también notable en la Santa Sede, donde los cardenales proborbónicos (como el cardenal del Giudice) y el propio embajador español en Roma, el duque de Uceda, se oponían al matrimonio de Felipe V con la hija del emperador. Carta de la princesa de los Ursinos a la mariscala de Noailles. Roma, 27 de diciembre de 1700, GEFFROY, 1859: 85-86.

28 Desde el gobierno de Carlos III los sucesivos duques de Saboya habían matrimoniado con hijas y nietas de los reyes de Portugal, España y Francia. La significación de estos enlaces, que situaron a la Casa de Saboya al nivel de otras importantes dinastías reinantes en Europa, fue reconocida por los diplomáticos extranjeros destinados en Turín. Por ejemplo, el duque de Giovenazzo admitió la tendencia de los duques de Saboya a «hacer casamientos grandes», así como sus «parentescos muy soberanos». Carta de Giovenazzo a Carlos II, Turín, 28 de febrero de 1677, AGS, E, leg. 3652. Sobre la política matrimonial de la Casa de Saboya, MERLOTTI, 2007: 87-133; 61/2 (París, 2009): 239-253.

29 Algunos aspectos de la educación de María Luisa pueden encontrarse en MERLOTTI, 41 (Bruselas, 2014): 29-45; 2008. Un análisis de la influencia política de las primeras consortes borbónicas en España, entre ellas las dos esposas de Felipe V, María Luisa de Saboya e Isabel de Farnesio, en NOEL, 2004: 155-185.

30 Casada con el primogénito del delfín y futuro heredero del trono francés. El resurgimiento a largo plazo de la tradicional rivalidad francoespañola constituyó uno de los aspectos que se debatieron en Versalles antes de la aceptación del testamento de Carlos II. Con objeto de evitar tal posibilidad, algunos ministros franceses abogaron por la futura celebración de distintos matrimonios entre príncipes y princesas de la rama francesa y la española de la dinastía. ÁLVAREZ LÓPEZ, 2008: 319-323. Acerca de la duquesa de Borgoña consúltense la recopilación de artículos coordinada por PRÉYAT, 41 (Bruselas, 2014) o el reciente trabajo, centrado en su formación como delfina de Francia en la corte de Versalles, de RIVA, 2015: 371-391. 
ciones precisas de su soberano, éste se redujo a informar de la inclinación del gabinete francés hacia el matrimonio saboyano, evitando otorgar una respuesta concluyente a las aproximaciones de Torcy ${ }^{31}$.

El silencio inicial de Vernon guardaba relación con el modo en que Víctor Amadeo II manejó sus relaciones con Versalles inmediatamente después del fallecimiento de Carlos II. El interés de Luis XIV en hacer de las nupcias de su nieto una parte esencial en la negociación del futuro acuerdo entre Saboya y las dos Coronas no pasó inadvertido al duque quien, por su parte, aspiraba a obtener los mayores beneficios posibles de su alianza con los Borbones, así como la más completa seguridad en cuanto al destino de su hija. Según indicó el embajador francés en Turín, Phélypeaux, Víctor Amadeo II diferenciaba entre sus propios intereses y los de su dinastía, siendo los primeros definitivamente más importantes que los segundos. Dicho en otras palabras, si bien el duque se sentía honrado con la elevación de su hija al rango de reina de España, ni podía resignarse a la pérdida del Milanesado ni quería renunciar a una posible expansión territorial de sus estados ${ }^{32}$.

Tales pretensiones condicionaron el posicionamiento de Víctor Amadeo II tras el advenimiento de los Borbones al trono español. La entronización de Felipe $\mathrm{V}$ inauguró un periodo de intensa interacción entre las diplomacias borbónica y saboyana. De acuerdo con las instrucciones de Luis XIV, Phélypeaux y Don Juan Antonio Albizu, designado enviado español en Turín a finales de 1700 , debían obtener del duque la autorización para que las tropas francoespañolas atravesaran el estado saboyano. Dicha gestión, que constituiría el prolegómeno del futuro tratado de alianza entre Saboya y las dos Coronas, fue iniciada sin éxito por Tessé y se prolongaría más tiempo del que Versalles había estimado en un principio ${ }^{33}$. La reticencia del duque a declararse abiertamente a favor de los Borbones cristalizó en las conversaciones paralelas que Turín mantuvo con los gobiernos francés e imperial desde la muerte de Carlos II. Con todo, conviene no exagerar la trascendencia de los tratos de Víctor Amadeo II con Viena en ese momento, situación que por otro lado era bien conocida en las redes diplomáticas europeas ${ }^{34}$. A la sazón, Leopoldo I afrontaba el conflicto sucesorio sin el apoyo de las potencias marítimas y en

31 Despachos de Vernon, París, 15 y 31 de diciembre de 1700, AST, LMF, Mazzo 128.

32 Carta de Phélypeaux a Luis XIV, Turín, 15 de enero y 5 de febrero de 1701, AMAEP, CPS, t. 107, fols. 32v. y 87r.

33 GRIMOARD, 1806, vol. I: 184. Sobre el papel de España en la negociación borbónico-saboyana véase LÓPEZ ANGUITA, 2012: 447-459. Si bien Víctor Amadeo II, a través de su Secretario de Estado, marqués de Saint-Thomas, había prometido que las tropas francesas acantonadas en Briançon tendrían absoluta libertad para atravesar sus estados en dirección a Milán, no tardó en retractarse de la promesa realizada.

34 Véanse a este respecto los testimonios de los representantes de la diplomacia veneciana en París, Viena o Milán recogidos en NICOLINI, 1937, vol. I: 187, 213-214 y 232. 
una situación de aparente inferioridad militar con respecto a las dos Coronas. Esta circunstancia no escapaba al duque quien, pese a insistir en que debía contemporizar con Versalles para eludir la agresividad francesa ${ }^{35}$, explicitaba sus condiciones para un futuro acuerdo borbónico-saboyano: «La Junta de Gobernación - declaró en su primer encuentro con Albizu - devía también hazer reflexión sobre sus intereses» ${ }^{36}$.

De entrada, Víctor Amadeo pretendía que las dos Coronas confirmaran el abandono definitivo de la opción matrimonial habsbúrgica y realizaran una petición oficial de la mano de su hija ${ }^{37}$. Paralelamente, ordenó a sus embajadores en París y Madrid que reclamaran los fondos que la corona española adeudaba a la Casa de Saboya en virtud tanto de los subsidios concedidos al duque durante la Guerra de los Nueve Años como de las dotes de la infanta Catalina Micaela y la princesa Isabel de Saboya, nunca satisfechas en su totalidad por la Monarquía Hispánica ${ }^{38}$. La alusión a estas deudas era absolutamente intencionada. A través de ella Víctor Amadeo II avanzaba una práctica ya desarrollada por sus predecesores: el interés de Turín en permutar lo adeudado por toda una serie de feudos fronterizos entre Saboya y el Milanesado, solicitud que el propio duque había realizado en los últimos años de vida de Carlos II ${ }^{39}$.

La estrategia de Víctor Amadeo II quedó de manifiesto cuando propuso a Albizu la cancelación de las deudas de la Corona española a cambio de diferentes territorios, sin especificar, en las Langas ${ }^{40}$. Aunque Albizu deploraba la

35 HAUSSONVILLE, 1901, vol. II: 364.

36 Despachos de Albizu, Turín, 19 de enero de 1701, BNE, mss. 10680, fol. 14r.

37 Carta de Phélypeaux a Luis XIV, Turín, 16 de enero de 1701, AMAEP, CPS, t. 107, fols. 37r.-v.

38 Despachos de Vernon, París, 15 de diciembre de 1700, AST, LMF, Mazzo 128. Despachos de Operti, Madrid, 19 y 31 de enero de 1701, AST, LMS, Mazzo 48. Un seguimiento de los pagos realizados por Madrid a Turín puede encontrarse en STORRS, 2013.

39 Estas peticiones fueron periódicas desde el gobierno de Carlos Manuel II y la regencia de su viuda, María Juana de Saboya. Víctor Amadeo II reiteraría las solicitudes de sus antecesores, centrando su atención en «diecinueve lugares» ubicados en el valle de Alessandria. Además, en 1695 envió al conde de Vernon a Madrid con el fin de obtener la cesión del valle de Sesia y su nombramiento como gobernador de Milán a cambio de las mesadas que se le adeudaban por su participación en la Guerra de los Nueve Años. Consultas del Consejo de Estado, Madrid, 24 de marzo, 13 de septiembre y 30 de diciembre de 1695, AGS, E, leg. 3671. La postura de los consejeros de Carlos II y el Senado de Milán, desfavorable a las demandas del duque, puede rastrearse en Consulta del Consejo de Estado, Madrid, 30 de diciembre de 1695, AGS, E, leg. 3657. Para la situación de estas peticiones durante la regencia de María Juana de Saboya, AGS, E, legs. 3668 y 3669.

40 Despachos de Albizu, Turín, 1 de febrero de 1701, BNE, mss. 10680, fol. 23v. Esta proposición se hacía eco de una de las ofertas que la Casa de Austria había realizado al duque en 1690, a través del marqués de Borgomanero, y que favoreció su intervención en la Guerra 
«indiferencia» con la que el duque respondía a sus reiteradas peticiones para la concesión del paso, estaba dispuesto a favorecer los intereses saboyanos ${ }^{41}$. Sin embargo, lamentablemente para Víctor Amadeo II, era Phélypeaux quien encabezaba la diplomacia borbónica en Turín, y el francés se mostraba bastante menos conciliador que su homólogo español.

A finales de enero de 1701 Versalles ordenó a su embajador solicitar al duque la mano de la princesa de Saboya en nombre del rey de España, proposición que Víctor Amadeo II aceptó tras tres días de reflexión. Tal requerimiento, junto con una oferta monetaria que contemplaría la subsistencia de las tropas francoespañolas en tierras saboyanas, era lo máximo que el gobierno francés estaba dispuesto a ofrecer ${ }^{42}$. A lo sumo, Luis XIV contemplaba la posibilidad de descontar la dote de la princesa María Luisa de las deudas de la corona española, propuesta que resultaba insuficiente al duque, quien proponía en contrapartida la cesión del Monferrato ${ }^{43}$. Esta opción sería igualmente desechada por el monarca francés. No en vano, el Monferrato estaba bajo soberanía del duque de Mantua, el único príncipe italiano que, junto a la princesa della Mirandola, era aliado de Francia ${ }^{44}$.

La intransigencia de Versalles ante sus proposiciones hizo que Víctor Amadeo II mantuviera su mutismo ante la concesión del libre paso. Cuando finalmente accedió a la demanda de las dos Coronas lo hizo debido a las presiones de Luis XIV. En efecto, el último día de enero de 1701 Operti recomendó a su señor que accediera a las solicitudes de Albizu y Phélypeaux

de los Nueve Años junto a los Aliados. CREMONINI, 2015: 204-205. Sobre el estatus de los feudos imperiales en Italia, MUSO, 2010: 67-120.

41 A comienzos de febrero de 1701 Albizu recomendó que Madrid diera al duque alguna muestra de parcialidad hacia sus intereses «pues en mi corto entender sería esta demostración muy conveniente» y «el único medio con que [...] inclinar, a lo menos en parte, su ánimo a lo más favorable en la presente constitución de las cosas». Despachos de Albizu, Turín, 6 de febrero de 1701, BNE, mss. 10680, fol. 24v.

42 Carta del duque de Saboya al conde de Vernon, [S. 1.], 26 de enero de 1701, AST, Matrimoni de Sovrani e Principi e Principesse della Reale Casa, Mazzo 38. Carta de Luis XIV a Phélypeaux. Marly, 20 de enero de 1701, el mismo al mismo, Versalles, 28 de enero de 1701, AMAEP, CPS, t. 107, fols. 48r., 50v. y 51r. La petición de Phélypeaux tuvo lugar en los primeros días de febrero. Carta de Phélypeaux a Luis XIV, Turín, 5 de febrero de 1701, AMAEP, CPS, t. 107, fol. 86v.

43 Vernon al duque de Saboya. París, 26 de enero de 1701, AST, LMF, Mazzo 130. El interés de la Casa de Saboya en el Monferrato databa de la década de 1610, cuando Carlos Manuel I aspiró a anexionarse el marquesado tras el fallecimiento sin sucesión de Francisco IV Gonzaga, duque de Mantua. Sobre la evolución de este territorio véase RAVIOLA, 2003.

44 Phélypeaux no otorgaba excesiva importancia a las deudas de la Corona española con la dinastía saboyana; o al menos a aquellas que procedían de las dotes de la infanta Catalina Micaela y su hija, la princesa Isabel. Tal y como informó a los ministros ducales, el impago de estas sumas era algo habitual en los matrimonios entre Casas soberanas. Carta de Phélypeaux a Luis XIV, Turín, 16 de enero de 1701, AMAEP, CPS, t. 107, fol. 44r. 
puesto que, de retrasar su respuesta, las tropas españolas acantonadas en Cataluña terminarían viajando a Italia por mar hasta Finale ${ }^{45}$. Por su parte, Vernon se mostró más explícito. En sus despachos a Turín el embajador aludió al ánimo «alterado» de Luis XIV; a la desconfianza de Torcy hacia Víctor Amadeo II, cuya actitud definió como un «galimatías» sólo explicable en función de sus tratos con el emperador; y, en definitiva, a la posibilidad de que el matrimonio del rey de España con María Luisa de Saboya no llegara a realizar$\mathrm{se}^{46}$. Ante tal perspectiva, el duque terminó por ceder a las exigencias francesas a mediados de febrero de $1701^{47}$. Tras la autorización del paso, sólo cabía pensar en la formalización del definitivo acuerdo borbónico-saboyano.

\section{LAS POSTURAS de Versalles Y TURín ANTE LA AliANZA: COACCIÓN Y DI- LACIÓN}

El tratado de alianza entre Saboya y las dos Coronas sería negociado por Phélypeaux. Por orden de Luis XIV el enviado español en Turín, Albizu, fue mantenido al margen ${ }^{48}$ de las conversaciones desarrolladas entre el embajador francés y los ministros ducales, marqués de Saint-Thomas, conde de Gropello, Mauricio Gubernatis y La Tour ${ }^{49}$. Interlocutor menos tolerante que Albizu hacia las ambiciones ducales ${ }^{50}$, Phélypeaux defendió con firmeza las condicio-

45 Despachos de Operti, Madrid, 31 de enero de 1701, AST, LMS, Mazzo 48.

46 Despachos de Vernon, París, 2 de febrero de 1701, AST, LMF, Mazzo 130.

47 Según Phélypeaux, el duque habría capitulado entre el 8 y el 9 de febrero de 1701. Carta de Phélypeaux a Luis XIV, Turín, 10 de febrero de 1701, AMAEP, CPS, t. 107, fol. 97v.

48 Carta de Luis XIV a Phélypeaux, Versalles, 21 de enero de 1701, AMAEP, CPS, t. 107, fol. 58v. Despachos de Albziu, Turín, 15 de febrero de 1701, BNE, mss. 10680, fols. 30r. y 33v. Si hemos de creer lo consignado en su correspondencia, Albizu reaccionó con resignación a las órdenes de Luis XIV. Otros diplomáticos españoles no se tomaron de igual modo su supeditación a la diplomacia francesa. Por ejemplo don Juan Carlos Bazán, predecesor de Albizu en Turín antes de ser destinado a Venecia, reconocía sentirse tratado como el «embaxador del Sultán de Constantinopla» por la diplomacia francesa, que le privaba de toda información respecto a las relaciones entre las dos Coronas y la República. Carta de Bazán al duque de Medinaceli, Venecia, 7 de mayo de 1701, BNE, mss. 3527, fol. 128v.

49 Saint-Thomas era secretario de Estado saboyano desde 1696; Gropello se convirtió en superintendente de finanzas en 1695 y Gubernatis ejercía como consejero y ministro de Estado desde 1700 . En cuanto a La Tour, había representado los intereses saboyanos ante las potencias marítimas durante la negociación de los Tratados de Reparto.

50 La relación de Phélypeaux con el duque era bastante tensa en el invierno de 1701 debido a las sospechas del diplomático hacia la lealtad de Víctor Amadeo II a los Borbones. Temeroso de que este hecho pudiera perjudicar la negociación del tratado de alianza, Luis XIV recomendó a su embajador que evitara toda alusión a los tratos del gobierno saboyano con la corte de Viena. Carta de Luis XIV a Phélypeaux, Versalles, 24 de febrero de 1701, AMAEP, CPS, t. 107, fols. 105r.-v. 
nes de Versalles para la formalización de la alianza borbónico-saboyana. En esencia estas reproducían las características del tratado de 1696, con la salvedad de que, mientras que cinco años antes Saboya había recuperado el control sobre Pinerolo y había obtenido la promesa de un hipotético apoyo francés a la conquista del Milanesado, de fallecer Carlos II durante la guerra de los Nueve Años, en la actualidad cualquier compensación territorial quedaba excluida de la alianza. En efecto, Luis XIV tan sólo se comprometía a conceder al duque subsidios económicos, que sufragarían su participación en el conflicto, además del título de generalísimo de los ejércitos borbónicos en Italia.

Como era de esperar, semejantes cláusulas resultaban intolerables para Víctor Amadeo, de ahí la reiterada insistencia de sus ministros en la posible anexión del Milanesado o, en su defecto, del Monferrato. Dispuesto a contemporizar, el duque proponía ahora que la cesión de cualquiera de estos territorios quedara al margen del tratado definitivo, formalizándose únicamente tras el fin del conflicto sucesorio. Por último, Víctor Amadeo II trató igualmente de que Versalles se comprometiera a continuar pagándole un subsidio, inclusive después del cese de las hostilidades ${ }^{51}$.

A través de Phélypeaux el gobierno francés se opuso a las diferentes condiciones planteadas por Turín. Junto con los subsidios negociados, el matrimonio de Felipe V con María Luisa de Saboya sería la principal gracia que Víctor Amadeo II obtendría del monarca francés. Ahora bien, en este aspecto de la negociación existía también una diferencia en relación a 1696: las nupcias del rey de España no formarían parte del nuevo tratado de alianza ${ }^{52}$. Con este planteamiento del asunto, Luis XIV esperaba forzar al duque a suscribir las condiciones del acuerdo propuesto por Francia manteniéndole en la incertidumbre con respecto al enlace de su hija. Según el monarca ordenó a Phélypeaux, éste no debía mencionar bajo ningún concepto el matrimonio de Felipe $\mathrm{V}$ durante la negociación del tratado ${ }^{53}$.

En estas circunstancias tuvo lugar el establecimiento de la alianza entre Saboya y las dos Coronas, formalizada en Turín el 6 de abril de 1701 y ratifi-

51 El gobierno saboyano estimaba que incluso después de descontar la dote de María Luisa de las deudas de la corona española con Turín, la suma adeudada por la Monarquía Hispánica, que Saboya cifraba en tres millones de libras tornesas, continuaría siendo lo suficientemente alta como para compensar la cesión del Monferrato. Despachos de Vernon, París, 26 de enero de 1701, AST, LMF, Mazzo 130. Carta de Phélypeaux a Luis XIV. Turín, 7 de abril de 1701, AMAEP, CPS, t. 107, fol. 98r.

52 La unión del duque de Borgoña con María Adelaida de Saboya aparecía recogida en el punto III del tratado franco-saboyano de 1696. SOLAR DE LA MARGUERITE, 1836, vol. II: 160.

53 Carta de Luis XIV a Phélypeaux, Versalles, 14 de marzo de 1701. LEGRELLE, 1897, vol. IV: 383; el mismo al mismo. Versalles, 30 de marzo de 1701, AMAEP, CPS, t. 107, fol. 180r. Despachos de Vernon, París, 30 de marzo de 1701, AST, LMF, Mazzo 130. 
cada por Luis XIV y Felipe V el 14 de abril y el 7 de mayo de ese mismo año respectivamente. Según lo estipulado con anterioridad, Víctor Amadeo II recibió la dignidad de generalísimo de los ejércitos borbónicos en Italia, además de subsidios por valor de 600.000 escudos anuales mientras durase el conflicto bélico. En contrapartida, el duque se comprometía a auxiliar a las tropas francoespañolas en Lombardía con 8.000 soldados de infantería y 2.500 de caballería. Para Symcox, el de 1701 constituyó un acuerdo francamente desfavorable a los intereses ducales. No en vano, Víctor Amadeo II contribuía a consolidar la posición de Felipe V en Italia al tiempo que Saboya, cercada por la Casa de Borbón, recuperaba la condición de satélite de Francia que había ostentado antes de $1690^{54}$. Dicho esto, no es menos cierto que, visto retrospectivamente, a comienzos de 1701 el duque tenía poco margen de maniobra en términos diplomáticos. Una alianza con la Casa de Austria tampoco le hubiera garantizado la anexión del Milanesado, su principal ambición, objetivo igualmente de la expansión imperial. En cuanto a la posible cesión del Monferrato, otra de las aspiraciones ducales, habría dependido de la capacidad de Viena para imponerse militarmente a las dos Coronas sin el apoyo de las potencias marítimas, lo que parecía poco factible en esos momentos ${ }^{55}$.

Pese a la formalización del acuerdo borbónico-saboyano, la tensión entre Versalles y Turín no disminuyó en lo sucesivo; tampoco clarificó el futuro matrimonial de María Luisa de Saboya a corto plazo. Recién constituida la entente, la situación era la siguiente. Por un lado, Luis XIV no estaba dispuesto a anunciar oficialmente las nupcias del rey de España hasta que el duque diera pruebas fehacientes de su lealtad a la Casa de Borbón. Por el otro, dado que su alianza con las dos Coronas era un hecho consumado, Víctor Amadeo II aspiraba a gozar ahora de la capacidad de maniobra que se le había negado durante la negociación de la misma. En ese momento los objetivos del duque radicaban, en primer lugar, en perpetuar los contactos que su gobierno había mantenido con el emperador; en segundo lugar, en retrasar lo máximo posible el cumplimiento de los compromisos adquiridos en su tratado con los Borbones, favoreciendo de este modo la toma de posiciones de los ejércitos

54 El tratado completo aparece recogido en SOLAR DE LA MARGUÉRITE, 1836, vol. II: 194-203. SYMCOX, 1983a: 139.

55 CARUTTI, 1879: 272-274. Por otra parte, las relaciones de Víctor Amadeo II con Guillermo III de Inglaterra no atravesaban un momento de fluidez. En abril de 1701 el Parlamento británico aprobó el Act of Settlement, que excluyó de la sucesión al trono a los descendientes católicos de los Estuardo. Entre los desposeídos de sus derechos sucesorios se encontraba Ana de Orleáns, esposa del duque y nieta de Carlos I de Inglaterra. Aunque Víctor Amadeo II elevó una protesta a través de su embajador en Londres, el conde de Maffei, la ley parlamentaria permaneció vigente y favoreció la posterior sucesión de los protestantes Hannover. CARUTTI, 1879: 293-294. 
imperiales ${ }^{56}$; y, por último, en concluir definitivamente el matrimonio de su hija ${ }^{57}$.

No es de extrañar, por lo tanto, que en las semanas que siguieron a la firma del tratado Víctor Amadeo II empleara diferentes excusas con el fin de demorar la partida de Turín de las tropas saboyanas que habían de sumarse a las francoespañolas en Lombardía ${ }^{58}$. En una muestra de conciliación, debida probablemente al hecho de que los ejércitos imperiales se encontraban ya reunidos en el Tirol, Luis XIV dispuso el anuncio oficial del enlace de Felipe V con María Luisa de Saboya, que tuvo lugar en Madrid el día 1 de mayo ${ }^{59}$. Un mes después, el 4 de junio, Phélypeaux otorgó al duque las cartas con las que el monarca español cumplimentaba a los miembros de la familia ducal. De manera deliberada, el rey de Francia dejó pasar un mes entre la oficialización de las nupcias y la entrega de tales misivas ${ }^{60}$. Un lapso de tiempo que había de servir para que Víctor Amadeo II esclareciera su buena voluntad hacia la alianza. No obstante, si bien desde mediados de mayo el duque comenzó a despachar parte de las tropas prometidas, que al decir de Albizu avanzaban a su destino con inusitada lentitud, persistió en su negativa a abandonar Turín y trasladarse al frente ${ }^{61}$.

56 Inmediatamente después de la firma del tratado borbónico-saboyano, Víctor Amadeo II ordenó a su embajador en Viena, marqués de Prié, que informara al emperador de su «interno e sincero desiderio di vederci un giorno aperta la strada a poterci unire alla Cesarea Maestà». Semanas después, el duque advirtió al mismo diplomático de la necesidad de mantener «un'occulta e impenetrabile corrispondenza» con el conde de Harrach, presidente del Consejo Imperial áulico. CARUTTI, 1879: 307-308. HAUSSONVILLE, 1901, vol. II: 354-355.

57 Preocupado por el silencio de Versalles, el duque sondeó la opinión de Madrid respecto a las nupcias del rey de España inmediatamente después de la firma del tratado. La respuesta que obtuvo de Operti no pudo ser más elocuente. Según indicó el diplomático, si bien Portocarrero y otros miembros del gobierno español eran decididos partidarios del matrimonio saboyano, no había duda de que la corte madrileña dejaría «che la Francia disponga di questo a suo gusto». Despachos de Operti, Madrid, 28 de abril de 1701, AST, LMS, Mazzo 48.

58 Los pretextos del duque guardaban relación con los problemas derivados tanto del reclutamiento de soldados como de las dificultades logísticas (pertrechos, indumentaria, hospitales militares, etc.). Despachos de Albizu, Turín, 26 de abril, 10 de mayo y 7 de junio de 1701, BNE, mss. 10680, fols. 57v.-58v.; 61r.-63v. y 74r.-75r.

59 Se trataba de 30.000 hombres al mando del príncipe Eugenio de Saboya, MCKAY, 2007: 66. Despachos de Operti, Madrid, 3 y 11 de mayo de 1701, AST, LMS, Mazzo 48. El anuncio oficial del matrimonio sería solemnizado en la corte española con cuatro noches de luminarias y un besamanos de la nobleza a Felipe V, BNE, mss. 12777, fols. 5r.-7r. A comienzos de ese mismo mes Víctor Amadeo II fue informado también de la futura designación de un embajador extraordinario que, en nombre del gobierno español, habría de reglar junto a los ministros ducales los distintos puntos del contrato matrimonial. Carta de Luis XIV a Phélypeaux, Versalles, 9 de mayo de 1701, AMAEP, CPS, t. 107, fol. 237r.

60 Las cartas de cumplimentación de Felipe $\mathrm{V}$ a la familia ducal habían sido redactadas en Versalles y remitidas a Madrid a comienzos de mayo a través de un correo ordinario. Consulta del Consejo de Estado. Madrid, 6 de mayo de 1701, AGS, Gracia y Justicia, libro 332.

${ }^{61}$ Despachos de Albizu, Turín, 21 de junio de 1701, BNE, mss. 10680, fol. 79v. 
La obstinada reticencia de Víctor Amadeo a cumplir con sus compromisos motivó un viraje sustancial en la estrategia de la corte francesa. A comienzos de junio Luis XIV abandonó todo talante contemporizador. Según reconoció a Phélypeaux, era consciente de los «vanos pretextos» empleados por el duque para diferir la ejecución de lo estipulado en el tratado. En consecuencia, si Víctor Amadeo II persistía en su actitud «je différerois [...] la conclusión d'un mariage aussy avantageux pour la Maison de Savoye» ${ }^{62}$. El enviado español, Albizu, recibió informaciones similares a las de su homólogo francés. A partir de ese momento el posicionamiento de la diplomacia borbónica sería inflexible. El duque había de reunirse en Goyto con Catinat, Tessé y Villerroy, los generales franceses destinados en Italia, junto a la totalidad de las tropas prometidas. En caso de no hacerlo, debía ser advertido de que Versalles suspendería no sólo la negociación del matrimonio del rey de España sino también el pago de los subsidios acordados por Francia en el tratado de abril de 1701.

Phélypeaux y Albizu cumplieron puntualmente las órdenes de Luis XIV. Según las instrucciones recibidas, ambos evitaron plantear el ultimátum del monarca francés al propio Víctor Amadeo. No obstante, aunque en su correspondencia ninguno de los dos citaba el nombre de sus respectivos interlocutores, el contenido del mensaje transmitido no dejaba lugar a la especulación. Valga como ejemplo el testimonio de Albizu. De acuerdo con el relato del enviado español, necesitó tres entrevistas con uno de los ministros ducales, «que tiene alguna confianza conmigo», para expresar cuán importante era que el duque «corriese con la debida puntualidad lo que había ajustado y prometido, tocándole aquí como de paso el real casamiento de Vuestra Majestad [...], pues lo contrario no podía producir sino embarazos y prejuicios» ${ }^{63}$.

La intervención de ambos diplomáticos resultó sumamente efectiva. Apenas unos días después de que se produjera, Víctor Amadeo II expresó su deseo de partir al frente en cuanto recibiera para ello órdenes expresas del rey de Francia. Como muestra de buena voluntad, anunció además su intención de enviar al campo de batalla ocho regimientos de infantería, uno de caballería y otro de Dragones. Con todo, el sometimiento del duque era relativo, puesto que continuaba insistiendo en permanecer en Turín durante la negociación de las capitulaciones matrimoniales de su hija, cuyo contenido aspiraba a supervisar personalmente ${ }^{64}$.

62 Carta de Luis XIV a Phélypeaux, Marly, 5 de junio de 1701, AMAEP, CPS, t. 107, fols. 265r.-266v.

63 Despachos de Albizu, Turín, 21 de junio de 1701, BNE, mss. 10680, fols. 80v.-81r. El testimonio de Phélypeaux a Luis XIV está fechado en Turín el 16 de junio de 1701, AMAEP, CPS, t. 107, fol. 284v.

${ }^{64}$ Cartas de Phélypeaux a Luis XIV, Turín, 16 y 20 de junio de 1701, AMAEP, CPS, t. 107, fols. 284v.-286r; 290r.-292v. 
En lo que constituía ya una pugna de voluntades de largo recorrido, Luis XIV no estaba dispuesto a tolerar más dilaciones del soberano saboyano. En razón de ello, a lo largo del verano el monarca francés tomó una serie de decisiones que amenazaban directamente las nupcias del rey de España. El matrimonio de Felipe $\mathrm{V}$ quedaba supeditado, una vez más, a la ejecución del tratado de abril de 1701 .

\section{EL GOBIERNO ESPAÑOL Y LA POLÍTICA DE HECHOS CONSUMADOS: EL FINAL DE LA NEGOCIACIÓN MATRIMONIAL}

Apenas tres meses después de la formalización de la alianza borbónicosaboyana las fisuras en su seno eran más que evidentes. La sospecha en torno a la naturaleza de las relaciones de Saboya con el Imperio constituía un factor que continuaba alentando la desconfianza de Luis XIV hacia la lealtad de Víctor Amadeo II a los Borbones. A este aspecto había que sumar, además, el contenido de los informes que el monarca recibía de sus generales en Italia, Catinat y Tessé, que aludían al perjuicio causado en la estrategia militar borbónica por la demora de la movilización de las tropas ducales ${ }^{65}$. Si las dos Coronas aspiraban a infligir una derrota rápida y contundente a las armas imperiales, las acciones del duque no favorecían tales propósitos. Todo lo contrario: en el verano de 1701 el príncipe Eugenio atravesó los Alpes, cruzó el río Adigio y derrotó a Tessé y Catinat en la batalla de Carpi (julio de 1701)66. Hasta el momento Luis XIV había esperado pruebas fehacientes del compromiso de Víctor Amadeo con la alianza, pero en la actual coyuntura las exigía, subordinando a ellas el destino definitivo de la princesa de Saboya.

Pocas fuentes son más ilustrativas a este respecto que una «Memoria» redactada por el gobierno francés relativa al viaje que Felipe $\mathrm{V}$ debía realizar a Italia. La visita del monarca a sus posesiones italianas había sido una opción contemplada por el gabinete de Versalles tras la entronización del soberano. En cualquier caso, nuestro interés no estriba tanto en las consideraciones político-diplomáticas que arroja este documento, interesantes en sí mismas, como en las reflexiones que contiene acerca de las nupcias del rey. En este sentido, los puntos 5 y 8 de la citada «Memoria» nos informan de un cambio importante en el planteamiento del matrimonio de Felipe V. De acuerdo con el contenido de los mismos, el monarca debería desembarcar en Finale donde, desde este mismo puerto o desde Génova, partiría en dirección al frente lombardo para ponerse a la cabeza de sus tropas. Una vez finalizada la campaña regresaría a Milán y, si el duque de Saboya «s'étoit bien conduit», se llevaría a

65 GRIMOARD, 1806, vol. I: 191-193.

66 MCKAY, 2007: 67. 
cabo su boda con la princesa María Luisa, tras la cual la pareja real partiría en dirección a Nápoles ${ }^{67}$. Así pues, la conducta de Víctor Amadeo definiría en último término el futuro de su hija.

A principios de julio Felipe $\mathrm{V}$ y el gobierno español fueron informados de las nuevas disposiciones de Versalles. Aunque el monarca acogió las órdenes de Francia con su docilidad habitual, consignó el chargé d'affaires francés, Monsieur de Blécourt, le manifestó su impaciencia por celebrar su matrimonio lo más pronto posible, opinión que también compartía el cardenal Portocarrero $^{68}$. Ante el cariz que tomaban los acontecimientos, éste se apresuró a hacer partícipe a Torcy de sus impresiones: «...el Rey mi Sr. desea grandemente la brevedad en la efectuación de su real cassamiento, y [...] es cierto lo desseo yo también, así por considerar el del Rey mi Sr., como porque sin duda es conveniente por todas consideraciones» ${ }^{69}$.

Pese a la aparente sumisión mostrada por el cardenal, lo cierto es que los acontecimientos posteriores pondrían de manifiesto su discrepancia con las últimas resoluciones de Luis XIV. Portocarrero era uno de los más firmes defensores del matrimonio entre Felipe V y la princesa de Saboya. De hecho, al tiempo que se expresaba ante Torcy en los términos que acabamos de ver, no dejó de presionar a Operti para que instara a su señor a unir sus tropas a los ejércitos francoespañoles acantonados en Italia, exponiendo al diplomático los problemas que afrontaba la ejecución del matrimonio regio ${ }^{70}$. En las semanas siguientes Portocarrero iría un paso más allá en sus decisiones. Ante la ansiedad del rey por concluir sus nupcias, el cardenal tomó una serie de medidas tendentes a acelerar y rematar la negociación matrimonial. Disposiciones que, en cualquier caso, contaron con el apoyo prácticamente unánime de los miembros del Consejo de Estado, órgano encargado de gestionar el regio matrimonio ${ }^{71}$.

67 «Mémoire sur la proposition du Roy d'Espagne de se rendre à la teste de ses armées d'Italie. Juillet 1701», AMAEP, CPE, t. 91, fols 44r.-70r. Los puntos 5 a 8 en fols. 61v.-64v. La idea del aplazamiento del matrimonio regio era apoyada también por el conde de Tessé por considerar, además, que no perjudicaría a las expectativas de sucesión al trono de España puesto que la princesa María Luisa no era aún núbil. Carta de Tessé a Chamillart, Camp de Goyto, 19 de junio de 1701, recogida en ESNAULT, 1885, vol. I: 34-35.

68 Carta de Blécourt a Luis XIV, Madrid, 9 de julio de 1701, AMAEP, CPE, t. 91, fol. 288v.

69 Carta de Portocarrero a Torcy, Madrid, 9 de julio de 1701, AMAEP, CPE, t. 91, fol. 293r.

70 Según las informaciones que el enviado veneciano en Madrid, Mocénigo, transmitió a su gobierno. Despachos de Mocénigo, Madrid, 6 de julio de 1701, recogido en NICOLINI, 1937, vol. II: 333.

${ }^{71}$ El interés en finalizar las nupcias de Felipe V no se limitaba a Portocarrero sino que fue expresado igualmente por otros consejeros del monarca, como los marqueses de Villafranca y del Fresno, quienes recomendaron dar inicio a la tramitación de la dispensa papal antes de concluir la negociación de las capitulaciones matrimoniales. Consultas del Consejo de Estado. Madrid, 5 y 9 de junio de 1701. AHN, E, leg. 2793. Acerca de la gobernación de la 
Designado embajador extraordinario ante la corte ducal, el marqués de Castel-Rodrigo partió hacia Saboya a mediados de julio, deteniéndose en Barcelona más tiempo de lo preciso a causa de las inclemencias climatológicas. En un momento determinado, debido a las recientes instrucciones de Luis XIV en torno a las nupcias del monarca, se planteó la posibilidad de que el marqués permaneciera en Lyon hasta recibir nuevas órdenes de Versalles, o que pretextara cualquier enfermedad con el fin de no dar inicio a la negociación matrimonial ${ }^{72}$. Sin embargo, apenas unos días después, el monarca francés cambió de opinión. Alarmado por la creciente hostilidad entre Víctor Amadeo II y Phélypeaux, así como por la difusión de ciertos rumores que aludían a la fragilidad de la alianza borbónico-saboyana, Luis XIV aceptó que CastelRodrigo avanzase hacia Turín. Con todo, y esto es algo que conviene tomar en consideración, en ningún caso el soberano autorizó al marqués a tratar las capitulaciones matrimoniales con el duque y sus ministros ${ }^{73}$.

A partir de ese momento los acontecimientos se precipitaron. Llegado a Turín el 17 de julio, Castel-Rodrigo siguió instrucciones de Portocarrero y finalizó, en apenas seis días, el contrato de matrimonio entre Felipe V y María Luisa de Saboya ${ }^{74}$. Temeroso de las consecuencias de una medida adoptada unilateralmente, Phélypeaux se negó a estampar su firma en el documento ${ }^{75}$.

Monarquía Hispánica con anterioridad a los cambios institucionales introducidos por los Borbones, BARRIOS, 2015. Sobre el funcionamiento y atribuciones del Consejo de Estado en el periodo moderno, BARRIOS, 1984.

72 Carta de Phélypeaux a Luis XIV, Turín, 6 de julio de 1701, AMAEP, CPS, t. 107, fols. 311v.-312r.

73 Carta de Luis XIV a Phélypeaux, Versalles, 9 de julio de 1701, AMAEP, CPS, t. 107, fol. 319r. Las circunstancias del viaje de Castel-Rodrigo hasta Turín aparecen recogidas en una carta del marqués a Antonio Ortiz de Otalora. Turín, 20 de julio de 1701, AHN, E, leg. 2793.

74 Carta de Castel-Rodrigo a Luis XIV, Turín, 23 de julio de 1701, AHN, E, leg. 2793. Carta del duque de Saboya a Operti, Turín, 23 de julio de 1701, AST, LMS, Mazzo 49. Inmediatamente después de la firma de las capitulaciones matrimoniales Castel-Rodrigo remitió correos a España, Nápoles y Roma con el fin de agilizar otros puntos relacionados con las nupcias regias: la preparación de las galeras que debían trasladar a María Luisa de Saboya hasta Barcelona y la obtención de la dispensa pontificia relativa a la consanguinidad de los contrayentes. Carta de Phélypeaux a Luis XIV, Turín, 24 de julio de 1701, AMAEP, CPS, t. 107, fols. 344r.-v.

75 Carta de Phélypeaux a Luis XIV, Turín, 24 de julio de 1701 y Carta de Luis XIV a Phélypeaux, Versalles, 3 de agosto de 1701, AMAEP, CPS, t. 107, fols. 344v. y 346r. Al contrario de lo sucedido con el tratado de alianza, las capitulaciones matrimoniales satisfacían parcialmente las exigencias del duque, particularmente en lo que concernía a la dote de María Luisa, que sería descontada del total de la suma adeudada por la Monarquía Hispánica a Saboya, y la renuncia de la princesa a sus derechos sucesorios sobre todos los territorios que conformaban el estado saboyano. El original en italiano de las capitulaciones, junto a la traducción en castellano, se encuentra en AHN, E, leg. 2461(2). Otra copia de ellas puede localizarse en Archivo General de Palacio, Histórica, caja 20, exp. 22. 
En cuanto al duque, partió al frente a la cabeza de sus tropas un día después, el 24 de julio, tranquilizado ya respecto al futuro de su hija ${ }^{76}$.

Así pues, Madrid había avanzado considerablemente las nupcias regias, pero estas distaban de estar concluidas definitivamente. En efecto, la respuesta de Luis XIV al proceder de la corte española no se hizo esperar. Enterado de lo sucedido en Turín, el monarca remitió a Felipe $\mathrm{V}$ una encendida misiva en la que le advertía de que, si bien Castel-Rodrigo había rematado las capitulaciones matrimoniales, su intención continuaba siendo la de retrasar por tiempo indeterminado la ejecución de sus nupcias ${ }^{77}$. Por su parte, Portocarrero y Castel-Rodrigo recibieron también sendas cartas desde Versalles. El primero del marqués de Torcy; el segundo del propio Luis XIV. En ellas se exponían toda una serie de directrices acerca de cuyo cumplimiento no debía caber duda alguna. Felipe $\mathrm{V}$ tendría que posponer su viaje a Barcelona (desde donde había de partir a Italia tras presidir las Cortes de Cataluña) y aguardar en Madrid hasta nueva orden. En cuanto al marqués, debía demorar la ejecución del matrimonio por poderes, que no se celebraría hasta que Luis XIV, informado sobre la conducta del duque de Saboya en el frente, así lo aprobara ${ }^{78}$.

Según relató posteriormente Blécourt, el soberano español aceptó el retraso en la celebración de sus bodas sin pena, a diferencia de Portocarrero y el presidente del Consejo de Castilla, Manuel Arias, «qui ne connoissent pas le caractère du duc de Savoye [et] n'estoient pas trop de ce sentiment ${ }^{79}$. Con todo, el cardenal evitó manifestar cualquier indicio de contrariedad ante Versalles. En su respuesta a la misiva que recibió de Torcy, asumió de nuevo un talante más moderado y colaborador, delegando la toma de decisiones en el gabinete francés $^{80}$. Así, de acuerdo con los dictados de Versalles, a comienzos de agosto el Consejo de Estado se negó a ratificar las capitulaciones matrimoniales. Disconforme con algunos de los puntos incluidos en ellas, el gobierno español consideró que Castel-Rodrigo se había excedido en las atribuciones que Felipe V le había otorgado como su embajador extraordinario. En consecuencia, los consejeros del monarca ordenaban diferir la celebración de los desposorios con el fin de «reparar o facilitar que se gane el tiempo» ${ }^{81}$.

76 Carta de Phélypeaux a Luis XIV, Camp de Goyto, 28 de julio de 1701, AMAEP, CPS, t. 107 , fol. 349 r.-v.

77 Carta de Luis XIV a Felipe V, Versalles, 29 de julio de 1701, AMAEP, CPE, t. 91, fol. 302r.

78 Carta de Torcy a Portocarrero, Marly, 29 de julio de 1701 y Carta de Luis XIV a Castel-Rodrigo, Versalles, 3 de agosto de 1701, AMAEP, CPE, t. 91, fols. 395r.-v.; 404r.$405 \mathrm{v}$. Órdenes similares recibió Phélypeaux por las mismas fechas. Carta de Luis XIV a Phélypeaux, Versalles, 3 de agosto de 1701, AMAEP, CPS, t. 107, fol. 346r.-347r.

79 Carta de Blécourt a Luis XIV, Madrid, 11 de agosto de 1701, AMAEP, CPE, t. 92, fol. 130r.

80 Cartas de Portocarrero y Ubilla a Torcy, Madrid, 9 de agosto de 1701, AMAEP, CPE, t. 92 , fols. 73 r.-74v. y 89 r.

81 Carta de Ubilla a Castel-Rodrigo, Madrid, 9 de agosto de 1701, AMAEP, CPE, t. 92, fols. 60r.-v. 
Pese a que el intento de la corte de Madrid por obrar con independencia de los designios de Luis XIV parecía haber fracasado, lo cierto es que fueron las decisiones tomadas por el cardenal Portocarrero las que finalmente determinaron las nupcias del rey de España. A lo largo del mes de agosto de 1701 las dificultades de Versalles para dilatar la conclusión del matrimonio del monarca español se hicieron cada vez más evidentes. De entrada, el retraso por tiempo indeterminado del viaje del rey a Barcelona no podía llevarse a cabo sin complicaciones, debido tanto a lo avanzado de los preparativos y gastos ya efectuados como a la importancia que el entourage francés de Felipe V otorgaba a la convocatoria de Cortes en Cataluña ${ }^{82}$. Por otro lado, al concluir Castel-Rodrigo las capitulaciones y partir el duque al frente, resultaba difícil aplazar el matrimonio por poderes sin concitar la oposición de Víctor Amadeo II y una posible reacción por su parte.

En el campo de batalla el soberano saboyano evidenciaba, a decir de Phélypeaux, que vigilaba estrechamente sus movimientos, un comportamiento exterior intachable, lo cual no era óbice para que se sintiera intimidado por las persistentes dudas de Catinat hacia su lealtad. Aunque el diplomático compartía los recelos del mariscal, consideraba una imprudencia que Luis XIV no autorizara la definitiva ejecución de las nupcias regias. Una situación que podía justificar el regreso a Turín de Víctor Amadeo II junto a sus tropas en plena campaña; o el más temible acercamiento definitivo de Saboya al Imperio ${ }^{83}$.

Ante el giro operado en los acontecimientos, el 21 de agosto de 1701 Luis XIV otorgó el plácet definitivo al matrimonio de Felipe V. La boda por poderes se celebró en Turín el 11 de septiembre de ese mismo año. A partir de ese momento María Luisa de Saboya podía considerarse reina de España. Sin embargo, la desconfianza seguiría muy presente en la alianza borbónicosaboyana y culminaría en su drástica ruptura apenas dos años después ${ }^{84}$.

\section{EPÍLOGo}

El establecimiento de la Gran Alianza de La Haya en septiembre de 1701 constituyó un elemento fundamental en la futura quiebra de una coalición borbónico-saboyana bastante erosionada a causa de las tensiones y desconfianzas

82 Sobre el viaje del monarca a Barcelona y la convocatoria de Cortes en Cataluña, PÉREZ SAMPER, 1 (Salamanca, 2000): 57-106. Una buena y reciente síntesis de las Cortes de 1702 en ALBAREDA, 2010: 77-89.

83 Carta de Phélypeaux a Luis XIV, Camp de Bornio, 18 de agosto de 1701; Carta de Phélypeaux a Luis XIV, Camp d'Antignano, 23 de agosto de 1701, AMAEP, CPS, t. 108, fols. 146r.-v. y $158 \mathrm{r}$.

84 Carta de Luis XIV al duque de Harcourt, Versalles, 21 de agosto de 1701, AMAEP, CPE, t. 92, fol. 140r. 
imperantes en su seno. De hecho, en los dos años que restaron hasta su ruptura, la alianza de Saboya con las dos Coronas distó de estabilizarse. Pese a que Víctor Amadeo II luchó con las tropas borbónicas en la batalla de Cremona (febrero de 1702), que junto a las de Carpi y Chiari otorgó una cierta superioridad a las armas imperiales sobre las borbónicas, nunca pudo superar el descontento que le suscitó el tratado de abril de 1701. La designación poco después del duque de Vendôme como nuevo general de las tropas francesas en Italia precipitó los acontecimientos. Mucho más dotado que su predecesor, el duque de Villeroy, Vendôme restableció el honor de las armas francesas y expulsó a los austriacos de sus posiciones en Parma y Mantua. Ese fue el momento elegido por Víctor Amadeo II para abandonar su alianza con los Borbones ${ }^{85}$.

Desde el verano de 1702 Viena y Turín protagonizaron un nuevo acercamiento clandestino que culminó, en noviembre de 1703, en el tratado suscrito entre Saboya y el Imperio, con las potencias marítimas como garantes del mismo. Negociado por el conde de Auersperg y Richard Hill, representantes del emperador y la reina de Inglaterra, en su negociación con el duque los aliados demostraron una mayor astucia que Francia. Básicamente porque, a diferencia de los Borbones, tomaron en consideración algunas de sus principales aspiraciones. En este sentido, Inglaterra concedió a Víctor Amadeo subsidios mensuales por valor de 80.000 escudos, al tiempo que Viena cedía en lo tocante a sus ambiciones territoriales al prometerle la futura anexión del Monferrato junto a ciertos territorios ubicados al oeste de Lombardía ${ }^{86}$.

El hecho de que los aliados realizaran unas ofertas innegablemente mejores que las que Francia hizo en su día, dotó a la integración de Saboya en la Gran Alianza de una perdurabilidad, que no estabilidad, que no puede adjudicarse a la coalición borbónico-saboyana. Visto retrospectivamente, parece que Víctor Amadeo II entendió su vinculación con las dos Coronas como una situación transitoria, algo que Luis XIV quizá nunca llegó a concebir. Al negociar el tratado de abril de 1701, el monarca francés adoptó un autoritarismo que parecía desmentir la importancia del ducado para la estrategia militar borbónica. Al mismo tiempo, Versalles planteó el enlace de Felipe V no sólo como un elemento que había de forzar al duque a aceptar un acuerdo altamente desfavorable a sus intereses, sino también, lo que a la larga resultó un error fatal, como una circunstancia que habría de garantizar a toda costa la fidelidad de Víctor Amadeo II a los Borbones.

A este respecto, las nupcias del rey de España constituyen un buen ejemplo de cómo los matrimonios de la realeza, pese a que con frecuencia eran parte fundamental de los acuerdos diplomáticos signados entre potencias,

85 MCKAY, 2007: 67-76. ALBAREDA, 2010: 130.

86 SYMCOX, 1983a: 140-143. SYMCOX, 1983b: 162. Para las negociaciones entre Turín y Londres, BLACKLEY, 1845. 
contribuían a establecer vínculos interdinásticos que no tenían por qué condicionar a medio y largo plazo la orientación de la política exterior de los Estados. En este sentido Luis XIV, que había sido el principal beneficiario de la reversión de alianzas de 1696, debería haber sabido que el enlace de su hija no coartaría la conducta del soberano saboyano en un contexto bélico e internacional que podía verse sujeto a cambios. Tanto más cuando algunas de las iniciativas del monarca francés a lo largo de 1701, por ejemplo el reconocimiento de Jacobo III como rey de Inglaterra o la entrada de las tropas francesas en la Barrera, parecían augurar el fin de la neutralidad de las potencias marítimas y la extensión de la guerra a nuevos frentes.

\section{BIBLIOGRAFÍA}

Albareda Salvadó, Joaquim, La Guerra de Sucesión de España (1700-1714), Barcelona, Crítica, 2010.

Álvarez López, Ana, La fabricación de un imaginario. Los embajadores de Luis XIV y España, Madrid, Cátedra, 2008.

Álvarez-Ossorio, Antonio, «Felipe V en Italia: el estado de Milán bajo la Casa de Borbón», en Eliseo Serrano (coord.), Felipe Vy su tiempo. Congreso Internacional, Zaragoza, Institución Fernando El Católico, 2004, vol. I: 775-842.

Arroyo Vozmediano, José Luis, El gran juego: Inglaterra y la sucesión española, tesis doctoral inédita [en línea], Madrid, UNED, 2012. Disponible en https://dialnet. unirioja.es/servlet/ tesis?codigo $=27076$ [consultado el 16 de agosto de 2016].

Barrios Pintado, Feliciano, El Consejo de Estado de la monarquía española (15211812), Madrid, Consejo de Estado, 1984.

Barrios Pintado, Feliciano, La gobernación de la monarquía de España: consejos, juntas y secretarios de la administración de corte (1556-1700), Madrid, Boletín Oficial del Estado, Centro de Estudios Políticos y Constitucionales, 2015.

Baviera, Adalberto de y Maura Gamazo, Gabriel, Documentos inéditos referentes a las postrimerías de la Casa de Austria en España. Volumen II (1698-1703), Madrid, Real Academia de la Historia, Centro de Estudios Políticos y Constitucionales, edición de 2004.

Beaucaire, comte de (ed.), Recueil des instructions données aux ambassadeurs et ministres de France depuis les traités de Westphalie jusqu'à la Révolution Française. Tome XIV. Savoie-Sardaigne et Mantoue, París, Félix Alcan Éditeur, 1898.

Bély, Lucien, «La Savoie entre Bourbons et Habsbourgs», en La Savoie dans l'Europe. Actes du XXXVIII Congrès des sociétés savantes de Savoie (Moûtiers, 9 et 10 septembre 2000), Moûtiers, Académie de la Val d'Isère, 2002: 225-236.

Bély, Lucien, "'Je n'aurais pas cru, Monsieur, que vous eussiez oublié que vous êtes italien'. L'Itaie et les Italiens pendant la guerre de Succession d'Espagne», en Lucien Bély, L'art de la paix en Europe. Naissance de la diplomatie moderne, XVI XVIII siècle, París, PUF, 2007: 407-429. 
Bély, Lucien, «La diplomacia europea y la partición del Imperio español», en En nombre de la Paz. La Guerra de Sucesión Española y los Tratados de Madrid, Utrecht, Rastatt y Baden, 1713-1715, cat. exp., Madrid, Fundación Carlos de Amberes, 2013: 51-75.

Bérenger, Jean, «La question de la Succession d'Espagne au XVII ${ }^{\mathrm{e}}$ siècle», en Lucien Bély (dir.), La présence des Bourbons en Europe XVI $-X X I^{e}$ siècles, París, PUF, 2003: 75-91.

Bérenger, Jean, Léopold I (1640-1705), fondateur de la puissance autrichienne, Paris, PUF, 2004.

Bérenger, Jean, «L'empereur Leopold $1^{\mathrm{er}}$, l'archiduc Charles et la succession d'Espagne», en Mercè Morales, Mercè Renom y Mamés Cisneros (coords.), L'aposta catalana a la Guerra de Successiò, 1705-1707, Barcelona, Generalitat de Catalunya, Museu d'Història de Catalunya, 2007: 73-84.

Blackley, William, The Diplomatic Correspondance of the Right Hon. Richard Hill, envoy extraordinary from the court of St. James to the Duke of Savoy..., Londres, John Murray, 1845.

Blum, Anna, La diplomatie de la France en Italie du Nord aux temps de Richelieu et de Mazarin, París, Classiques Garnier, 2014.

Carutti, Domenico, Storia della diplomazia della corte di Savoia. Vol. III, $2^{\circ}$ periodo, 1663-1730, Turín, Fratelli Bocca, 1879.

Cremonini, Cinzia, «El príncipe de Vaudemont y el gobierno de Milán durante la guerra de Sucesión española», en Antonio Álvarez-Ossorio, Bernardo García García y Virginia León Sanz (eds.), La pérdida de Europa. La guerra de Sucesión por la Monarquía de España, Madrid, Fundación Carlos de Amberes, 2007: 463-490.

Cremonini, Cinzia y Muso, Riccardo (eds.), I feudi imperiali in Italia tra XV e XVIII seccolo, Roma, Bulzoni, 2010.

Cremonini, Cinzia, «Trayectorias distinguidas en tiempos de Carlos II. Carlos Manuel de Este, marqués de Borgomanero, entre Milán, Madrid y Viena», en Bernardo García García y Antonio Álvarez-Ossorio (eds.), Visperas de sucesión. Europa y la Monarquía de Carlos II, Madrid, Fundación Carlos de Amberes, 2015: 183-208.

Esnault Gaston, Michel de Chamillart. Controleur Général des Finances et Secrétaire d'Etat de la Guerre (1699-1709). Correspondance et papiers inédits, Tome Premier, París, Alphonse Picard Éditeur, 1885.

Frey, Linda y Frey, Marsha, A question of Empire: Leopold I and the war of Spanish succession, 1701-1705, Nueva York/Boulder, East European Monographs/Columbia University Press, 1983.

Galasso, Giuseppe (dir.), Storia d'Italia. Vol. 8. Il Piemonte sabaudo. Tomo I. Stato e territori in età moderna, Turín, UTET, 1994.

Geffroy, Auguste (ed.), Lettres inédites de la princesse des Ursins, París, Didier et Cie, 1859.

Grimoard, comte de, Mémoires et lettres du Maréchal de Tessé, contenant des anecdotes et des faits historiques inconnus, sur partie des règnes de Louis XIV et de Louis XV, París, Treuttel et Würtz, 1806. 
Handen, Ralph D., «The end of an Era: Louis XIV and Victor Amadeus II», en Ragnhild Hatton (ed.), Louis XIV and Europe, Londres, Macmillan, 1976: 241-260.

Haussonville, comte de, La Duchesse de Bourgogne et l'alliance saboyarde sous Louis XIV. Vol. II: Les années heureuses et la rupture de l'alliance, París, Calmann-Lévy, 1901.

Hippeau, Célestin, Avènement des Bourbons au trône d'Espagne. Correspondance inédite du Marquis de Harcourt, Paris, Didier, 1875.

Kampmann, Christoph, «Leopoldo I: la política imperial, los derechos dinásticos y la sucesión española», en Luis Ribot y José María Iñurritegui (eds.), Europa y los tratados de reparto de la Monarquía de España, 1668-1700, Madrid, Biblioteca Nueva, 2016: 173-194.

Lecestre, Léon (ed.), Mémoires de Saint-Hilaire. Tome Troisième, 1697-1704, París, H. Laurens, 1809.

Lecestre, Léon (ed.), Mémoires du Chevalier de Quincy. Tome Premier (1690-1703), París, Renouard, 1898.

Legrelle, Arsène, La diplomatie française et la succession d'Espagne. Vol. IV: La crise (1700-1702), Braine-le-Comte, Zech, 1897.

López Anguita, José A., «Entre la colaboración y la supeditación. La embajada de Don Juan Antonio Albizu en Turín y la firma del tratado de alianza borbónicosaboyano de 1701», en Antonio Jiménez Estrella y Julián Lozano Navarro (eds.), Actas de la XI Reunión Cientifica de la Fundación Española de Historia Moderna. Comunicaciones. Volumen I: El Estado Absoluto y la Monarquía, Granada, Universidad Granada, 2012: 447-459.

Malettke, Klaus, «La signification de la Succession d'Espagne pour les relations internationales jusqu'à l'époque de Ryswick (1697)», en Lucien Bély (dir.), La présence des Bourbons en Europe XVI ${ }^{e}-X X I^{e}$ siècles, París, PUF, 2003: 93-100.

Martín Marcos, David, El Papado y la Guerra de Sucesión española, Madrid, Marcial Pons Historia, 2011.

Martín Marcos, David, Península de recelos. Portugal y España, 1668-1715, Valladolid/Madrid, Instituto Universitario de Historia Simancas, Marcial Pons, 2014.

McKay, Derek, Eugenio di Savoia. Ritratto di un condottiero, 1663-1736, Turín, Società Editrice Internazionale, 2007.

Merlotti, Andrea, «I Savoia: una dinastia europea in Italia», en Walter Barberis (ed.), I Savoia. I secoli d'oro di una dinastía europea, Turín, Eiunadi, 2007: 87-133.

Merlotti, Andrea, «Politique dynastique et alliances matrimoniales de la Maison de Savoie au XVIIe siècle», XVIIe siècle, 61/2 (París, 2009): 239-253.

Merlotti, Andrea, «La courte enfance de la duchesse de Bourgogne (1685-1696)», en Fabrice Préyat (ed.), Marie-Adélaïde de Savoie (1685-1712), duchesse de Bourgogne, enfant terrible de Versailles, XVIII. Études sur le $18^{e}$ siècle, 41 (Bruselas, 2014): 29-45.

Meuvret, Jean, «Louis XIV et l'Italie», XVII siècle, 46/47 (París, 1960): 84-102.

Michelet, Jules, Histoire de France. XIV. Louis XIV et le duc de Bourgogne, edición de Paul Viallaneix et Paule Petitier, París, Éditions des Équateurs, 2008. 
Moscati, Ruggeri, Direttive della politica estera sabauda da Vittorio Amedeo II a Carlo Emanuele III, Milán, Istituto per gli Studi di Politica Internazionale, 1941.

Murgia, Giovanni, «La Guerra de Sucesión española en Italia,» en Francisco García González (coord.), La Guerra de Sucesión en España y la batalla de Almansa, Madrid, Sílex, 2009: 187-229.

Musso, Roberto, «I feudi imperiali delle Langhe tra Impero e Stato di Milano (XVXVIII seccolo)», en Cinzia Cremonini y Roberto Musso (eds.), I feudi imperiali in Italia tra XVI e XVIII seccolo, Roma, Bulzoni, 2010: 67-120.

Nicolini, Fausto (ed.), L'Europa durante la Guerra di Successione di Spagna, Vol. I, Nápoles, Reale Deputazione Napoletana di Storia Patria, 1937.

Noel, Charles C., “'Barbara succeeds Elizabeth...’: the feminisation and domestication of politics in the Spanish Monarchy, 1701-1759», en Clarissa Campbell-Orr (ed.), Queenship in Europe, 1660-1814. The role of the consort, Cambridge, Cambridge University Press, 2004: 155-185.

Nordmann, Claude, «Louis XIV and the Jacobites» en Hatton Ragnhild (ed.), Louis XIV and Europe, Londres, Macmillan, 1976: 82-111.

Oresko, Robert, "The House of Savoy in search of a royal Crown in the seventeenth century», en Robert Oresko et al. (eds.), Royal and Republican Sovereignty in Early Modern Europe. Cambridge, Cambridge University Press, 1997: 272-350.

Oresko, Robert, «Princesses in power and european dynasticism: Marie-Christine of France and Navarre and Maria Giovanna Battista of Savoye-Genevois-Nemours, the last regents of the House of Savoy in their international context», en Franca Varallo (ed.), In assenza del re. Le reggenti dal XIV al XVII secolo (Piemonte ed Europa), Florencia, Leo S. Olschki, 2008: 393-434.

Pérez Samper, María de los Ángeles, «Felipe V en Barcelona: un futuro sin futuro», Cuadernos Dieciochistas, 1 (Salamanca, 2000): 57-106.

Preyat, Fabrice (ed.), «Marie-Adélaïde de Savoie (1685-1712). Duchesse de Bourgogne, enfant terrible de Versailles», XVIII. Études sur le $18^{e}$ siècle, 41 (Bruselas, 2014).

Raviola, Blythe A., Il Monferrato gonzaghesco. Istituzioni ed élites di un micro-Stato (1536-1708), Florencia, Leo S. Olschki, 2003.

Reineri, Maria Teresa, Anna Maria d'Orleans. Regina di Sardegna, Duchessa di Savoia, Turín, Centre di Studi Piemontesi, 2006.

Ribot, Luis e Iñurritegui, José María (eds.), Europa y los tratados de reparto de la Monarquía de España, 1668-1700, Madrid, Biblioteca Nueva, 2016.

Ribot, Luis, «Los tratados de reparto de la Monarquía de España. Entre los derechos dinásticos y el equilibrio europeo», en Luis Ribot y José María Iñurritegui (eds.), Europa y los tratados de reparto de la Monarquía de España, 1668-1700, Madrid, Biblioteca Nueva, 2016: 29-53.

Riva, Elena, «Un’ educatrice alla corte del re Sole. Il caso della marchesa di Maintenon e della defina di Francia Maria Adelaide di Savoia», en Chiara Continisio y Marcello Fantoni (eds.), Testi e contesti. Per Amedeo Quondam, Roma, Bulzoni Editore, 2015: 371-391.

Riva, Elena, «La crisi dinastica e le reti di potere cortigiane nei dispacci degli ambasciatori sabaudi a Madrid. Alcune linee di ricerca», en Marcella Aglietti, Alejandra 
Franganillo Álvarez y José A. López Anguita (eds.), Élites e reti di potere. Strategie d'integrazione nell'Europa di età moderna, Pisa, Pisa University Press, 2016: 199-213.

Rosso, Claudio, «Le due Cristine: Madama Reale fra Agiografia e Leggenda Nera», en Franca Varallo (ed.), In assenza del re. Le reggenti dal XIV al XVII secolo (Piemonte ed Europa), Florencia, Leo S. Olschki, 2008: 367-392.

Rowlands, Guy, «Luis XIV, Vittorio Amadeo II and French Military Failure in Italy, 1689-1696», The English Historical Review, 115/462 (Oxford, 2000): 534-569.

Solar de la Marguerite, Clement, Traités Publics de la Royale Maison de Savoie avec les puissances étrangères depuis la Paix de Château-Cambresis jusqu'à nos jours, Tome II, Turin, Imprimerie Royale, 1836.

Spagnoletti, Angelantonio, Le dinastie italiane nella prima età moderna, Bolonia, Il Mulino, 2003.

Storrs, Christopher, «Machiavelli Dethroned: Victor Amadeus II and the Making of the Anglo-Saboyard Alliance of 1690», European History Quarterly, 22/3 (Londres, 1992): 347-381.

Storrs, Christopher, War, diplomacy and the rise of Savoy, 1690-1720, Cambridge, Cambridge University Press, 1999.

Storrs, Christopher, «Savoyard diplomacy in the Eighteenth century (1684-1798)», en Daniela Frigo (ed.), Politics and Diplomacy in Early Modern Italy, Cambridge, Cambridge University Press, 2000: 210-252.

Storrs, Christopher, «La politica internazionale e gli equilibri continentali», en Walter Barberis (ed.), I Savoia. I secoli d'oro di una dinastía europea, Turín, Eiunadi, 2007: 3-47.

Storrs, Christopher, La resistencia de la Monarquía Hispánica, 1665-1700, Madrid, Actas, 2013.

Storrs, Christopher, «Los tratados de reparto, la revolución de la política exterior inglesa y el caso de Saboya», en Luis Ribot y José María Iñurritegui (eds.), Europa y los tratados de reparto de la Monarquía de España, 1668-1700, Madrid, Biblioteca Nueva, 2016: 217-245.

Symcox, Geoffrey, Victor Amadeus II. Absolutism in the Saboyard State, 1675-1730, Berkeley/Los Angeles, University of California Press, 1983.

Symcox, Geoffrey, «Britain and Victor Amadeus II: or the use and abuse of allies», en Stephen B. Baxter (ed.), England's rise to greatness, 1660-1763, Berkeley/Los Ángeles/Londres, University of California Press, 1983: 151-184.

Symcox, Geoffrey, «Dinastia, Stato, Amministrazione», en Walter Barberis (ed.), I Savoia. I secoli d'oro di una dinastía europea, Turín, Einaudi, 2007: 49-86.

Thomson, Mark A., «Louis XIV and the origins of the War of the Spanish Succession», en Ragnhild Hatton y John S. Bromley (eds.), William III and Louis XIV. Essays by and for Mark A. Thomson, Liverpool, Liverpool University Press, 1968: 140-159.

Recibido: 31/10/2016

Aprobado: 04/07/2017 